\title{
Re-print
}

\section{Toward a Definition of Moving-Picture Dance}

\author{
Noël Carroll
}

[Ed. note: This article was originally presented as a paper at the "Dance for the Camera Symposium" at the University of Wisconsin-Madison in 2000, and subsequently published in the Summer 2001 issue of Dance Research Journal.]

Imost since their inception, moving pictures have often featured dance. The obvious
reason for this is that the natural subject of moving pictures is movement. And
dances_-along with hurtling locomotives, car chases, cattle stampedes, tennis matches, intergalactic dogfights, and the like-move. Thus, a significant portion of the history of moving pictures involves dance movement. Many moving-picture makers have devoted admirable amounts of effort and imagination to portraying dance in or through media as diverse as film, video, and computer animation. The purpose of this essay is to attempt to offer a philosophical characterization of this field of activity; that is, I will try to define moving-picture dance.

Many readers, learning of my intention, are apt to groan, "labeling again, how boring." To a certain extent I can sympathize with that sentiment. It is far more interesting to talk about work than it is to set about classifying it. The concrete achievements of the field are more important than abstractions about it. Nevertheless, and despite my ready acknowledgment of this, I will persist for several reasons.

First, whenever festivals of this sort of work are held, it is very likely that at one time or another almost everyone present will be tempted to say of some work that it doesn't really belong on the program. Everyone complains about labeling, but sooner or later most people feel compelled to invoke some favorite definition of their own. For human beings, categorizations are unavoidable, even if we like to pretend indifference to them. And most of us can feign indifference only for so long; most of us have a breaking point. Thus, it seems to me a good idea to get this issue out in the open and to discuss it abstractly — to compare and contrast the various categorizations in play and to develop dialectically from them a comprehensive framework that makes sense of our practices and that resonates with our intuitions about its compass.

Second, though defining things can be a tedious affair, it is also a very powerful way to learn about the contours of a field. For when we attempt to define the strengths and weaknesses of alternative and even rival proposals, we come to recognize the complexity of the field, since different definitions will highlight certain tendencies in the work in question, even if they obscure others. Definitions, that is, even when they are unsuccessful, as I suspect mine might be, can be illuminating. For definitions do not merely demarcate the 
boundary of a field from other fields, but they can reveal the intricate landscape within a field as well.

Definitions, in short, have a heuristic or pragmatic use, often perspicuously flushing out data and complications previously neglected, ignored, overlooked, or unappreciated. This is true even where the definition turns out to be ultimately unsatisfactory. So even though my definitions may appear either too narrow or too broad, I offer them as a way of advancing the discussion.

Another reservation about definitions, popular in the humanities today, is the suspicion that all definitions are covert exercises of power, privileging some work and disenfranchising other work. I am skeptical of this general position about definitions and, in the concluding passages of this paper I will try to show why my definitions of motion picture dance are not an ideological brief in favor of some stylistic practices rather than others. Thus, though I will not be in a position to defend that view until you have read my proposals and arguments on its behalf, let me at the outset of this definitional exercise at least register the plea that my intention here is not to create a definition that is stylistically exclusive; rather, I will attempt to craft a category that is as broad as possible, while at the same time being something we are willing to count as a genuine category.

Indeed, I am motivated to construct a broad category of moving picture dance just because I think that existing ways of defining the field are too narrow-too narrow especially in ways that cause friction, as creative artists attempt to exploit new technologies. For example, those who classify the field in question as cine-dance wonder whether computer animations of dance should be at the same festival or on the same program or in the same historical overview as works by Maya Deren. Many ways of construing the field, that is, are wedded to certain moments in the development of moving-picture technology, such as the heyday of film. But conceiving of the field only in terms of film stands athwart historythat is, it blocks the prospects, conceptually and sometimes practically, of an innovative engagement on the part of makers of dance images with new technologies.

It seems obvious that alternative technologies for the creation of motion picture dance will continue to proliferate. In order to facilitate experimentation, we will need a broad conception of the field, one that will make the exploration of previously undreamtof possibilities easier, rather than closing down options. It is in that spirit that I have offered the present definition - to invite change and development, rather than to defend the status quo. In fact, I see my definition, in contrast to existing alternatives, as a means of emancipating creativity, at least in terms of promoting openness to the inevitability of technological change, rather than as a strategy for canonizing entrenched stylistic practices. Perhaps someone will discover a way in which my proposals serve some hidden dance-world agenda. But one must spell that out in letter and verse. One cannot presume a priori that all definitions serve the interests of some vaguely defined establishment. Some may even liberate.' Whether mine does or not remains to be seen.

Undoubtedly, you will have already noticed that I have introduced a new name, "Moving-Picture Dance," for the field under discussion. I have opted for this conceptualization rather than other, more familiar ones, such as cine-dance, film dance, video dance, camera dance, and even screen dance. One way to begin to approach the problem of defining the field is to articulate the reasons for preferring one mode of nomenclature rather than others. 
Traditionally, the area has been called cine-dance or film dance. Since cine-dance is probably the most popular way of referring to the field, it is worthwhile to spend some time explaining its limitations. The problem with characterizing the field in terms of cine-dance is that it is too narrow. Obviously, it is too medium specific. It restricts the phenomenon to work made in cinema or film. It is, so to speak, a celluloid-based conception. It also perhaps belies the modernist bias behind much early work in this area. That is, it seems to suppose that each artistic medium has its own peculiar limitations and/or potentialities, and that it is the duty of the artist to foreground those unique features of the medium in her work. Thus, many have thought that for a candidate truly to belong to the corpus of cine-dance it would have to exploit the unique features of cinema, where those are customarily understood in contrast to the possibilities and limitations of theater, including theater dance.

Cine-dance or film dance, under this construal, is always avant-garde, inasmuch as it is implicitly allied to modernist commitments to the purity of the medium. For example, Ed Emshwiller claims:

To me there are characteristics that distinguish cine-dance from a straight dance film. When the dancer is used in filmic terms, rather than dance terms, space, and time are flexible. The images projected on the screen may seem to move forward and backward in time, may be discontinuous, in fast motion, slow motion, frozen, repetitious, or simultaneous. The dancer can appear to shift instantaneously from one location to another, can be compressed, elongated, distorted, or seen from widely varying perspectives. These manipulations are some of the means the filmmaker has to choreograph his work. By means of the camera and the editing table, he creates image movements and relationships different from those of the dance choreographer. $(25)^{2}$

Though this view was once extremely enabling, this conception of the phenomenon is at present clearly obsolete for two reasons. First, by now the work that we all agree belongs to the field in question includes all sorts of work in media other than cinema. Video is the most obvious exception. But also, work which no one would deny falls into the category that concerns us can be achieved through computer processing, such as the technique known as motion capture, which was used in the production of Bill T. Jones's Ghostcatching (1999).

If film was the medium in which endeavors of the kind that concern us first appeared, that fact can be regarded, in one sense, as an accident of history. For the visual culture established in the film medium has evolved and been refined by other media, and is likely to undergo even further development in media not yet imagined. This is why, rather than speaking of film studies or cinema studies, I prefer the concept of moving-image studies, which includes as its object not only film, TV, video, laser discs, and CD-ROM, but also whatever else is to come as future technologies abound and generate descendents of our current moving-image practices. ${ }^{3}$ Similarly, this is why I think that we should speak of moving-picture dance rather than cine-dance, film dance, and, for the same reason, video dance, since these categories insofar as they are each medium specific, are too restrictive. The phenomenon at hand crosses media, and, therefore, calls for a label that reflects this fact.

A second reason to eschew medium-specific characterizations of the field is related to the implicit modernist prejudices concerning the purity of the medium that often come in tandem with this way of speaking. In the modernist conception, a cine-dance should be uniquely cinematic, or uniquely videomatic — that is, something realizable only in film (or video), and not by means of some other medium of expression, notably theater. Thus, Talley 
Beatty's famous leap in Maya Deren's A Study in Choreography for the Camera (1945)-a legendary example of Doug Rosenberg's notion of recorporealization ${ }^{4}$ —is regarded as a quintessential example of cine-dance, for a grand jeté of that length would be humanly impossible on stage, but is rather an artifact of what some might call film-space and film-time. ${ }^{5}$

But this modernist bias is overly exclusive. On the one hand, what is called "film-space" and "film-time" are realizable in other media, including, if not theater, then at least video. ${ }^{6}$ And, on the other hand, it is far from evident that whether or not something is realizable theatrically is the relevant criterion here. This approach, as we saw in the previous quotation from Emshwiller, seems to favor editing and special effects as the true tests for membership in the class of cine-dances. But, as Roger Copeland has pointed out, we may wish to include in the relevant category dances, such as some numbers by Fred Astaire and Ginger Rogers, that, though made for the camera, are executed in long-take, deep-focused shots that capture movement in a continuous space (11)?

Do we wish to exclude these-which might be called "Bazinian cine-dances"—from our perspective, just because it is conceivable that they could be staged in real time on the space of a theater stage? ${ }^{8}$ Likewise, something like David Woodberry's Invisible Dance (1981), a Tati-like exercise in discovering dance amidst the flow of everyday life could be refashioned as an instance of street theater. ${ }^{9}$ But still, the version of Invisible Dance that we possess on film, I think, is something that most of us would agree is a cine-dance or, at least, whatever we wind up calling this category.

Indeed, the same point might be made with respect to Elliot Caplan and Merce Cunningham's Beach Birds for Camera (1993), since not only is it artistically impure, given its self-avowedly painterly ambitions, but also, with enough money, enough elaborate set machinery (including rotating stages), and an arsenal of lighting effects, something very like it could arguably be realized theatrically. And yet it belongs to the category that concerns us.

Of course, by arguing that this category should not be tied to a specific medium, I do not mean that the artist should ignore the medium in which she is working, but only that the medium and certain favored uses of the medium should not be the test of class membership here. The artist is well advised to understand the capabilities of her materials, including the lenses, film stocks, chromakeys, and the like which she intends to deploy. The point is simply that which of these media and their capabilities she chooses does not determine whether her work is an instance of what I call moving-picture dance.

My dismissal of the physical medium as criterial in this regard may strike some as too hasty. For the notion of a medium can refer not only to the materials from which an artwork is constructed, but also to the implement used in constructing it. Not only sounds, but also musical instruments, like clarinets, can be referred to as musical media. And, in this sense, it may seem that everything in the category of moving-picture dance shares a mediuman instrument through whose agency they are all contrived. And that instrument is the camera. So why not call the category camera-dance or dance for the camera?

There are several problems with this proposal. The first is that there are so many different kinds of cameras that one hesitates to say that we've got hold of a single medium here. Further, one can imagine moving-picture dance imagery generated not by a camera but by means of sound - sonograms, after the fashion of radar. But, as well, in a less science-fiction 
vein, we may worry that thinking in terms of camera-dance is too restrictive. Are there not animated dances, which, though they depend on cameras to be mass-produced, are primarily the result of drawing rather than photography? And would a dance composed exclusively in the realm of CD-ROM by computer animation and exhibited on computer monitors be discounted from a festival of work of the relevant sort, merely because it was not camera generated? This is another reason why I prefer the label moving-picture dance to the alternative label camera-dance.

The notion of screen dance, which I myself once found very promising, may seem to avoid the kinds of problems we've encountered so far. For it might be supposed that it is not medium specific; screens, it might be said, are shared by films, video, TV, and computer monitors. But, though this may seem perverse on my part, I think that this supposition is false, if we take the notion of a screen literally.

A screen, in the pertinent sense, is a support upon which we project an image. But, in this respect, a screen is not a necessary condition for a showing even a film. As is well known, Edison originally had the idea that films would be shown at peep shows, on devices that we would now call movieolas. It remained for the Lumieres to project films onto screens. Thus, early dance films like Annabelle the Dancer (1894-1895) and possibly Crissie Sheridan (1897) were not examples of screen dance. Moreover, the movieola/peepshow circuit did not end with the Lumieres. From my adolescence I remember peepshows of exotic dancers and strippers, available on coin-operated movieolas in amusement parks and adult bookstores. Nor were these films only single-take documentations of prior theatrical performances: many were made for the camera and edited. Films do not need to be literally screened or even to be destined for screening in order to count as films, and, therefore, there can even be film dances that are not screen dances.

Another problem with the notion of screen dance is that the concept of a screen does not really apply to television, though certainly televised dance should not be automatically excluded from our catch area. Televisual images are not projected onto a screen. We look directly into them; we do not look at their reflections or projections on a screen. Standardly, film scholars attempt to distinguish between film viewing and TV viewing this way. Because of movieolas, I do not think that this distinction is as ironclad as they do. But still, they make a legitimate point about the typical TV viewing apparatus (rather than, say, cassette projectors): in the usual case, we look into the projection and not at a reflection of the projection. The same can be said about looking at moving images on computer monitors.

Denying that TV images of dance are literally cases of screen dance may strike some as outlandish. After all, we talk about TV screens all the time. But what does this mean? Is the TV screen the front glass on the monitor-the thing that people clean with Windex and sometimes call a screen? But this is not a screen properly so called. That is, it is an entirely different animal than a film screen. For first of all, the TV image is projected through this glass and not onto it. And second, this glass is not a necessary feature of the TV image. You can remove it and there will still be a moving image. Try it, if you don't believe me.

Perhaps what people have in mind when they talk about the TV screen is the phosphor screen in the cathode ray tube. This lies between the shadow mask and the front of the glass of the picture tube. It is coated with phosphor strips that glow when different colored beams of light hit it. But the phosphor screen is part of the picture tube-which is to say that it is part of the projection mechanism, i.e., once again, part of the picture 
tube. It is not a screen onto which the image is projected. It is a device for generating the image; it is a device for projecting the image. Typically, there is no screen onto which the projector beam throws the image. In television, we usually look directly into the projection mechanism rather than at a screen onto which something is projected. Thus, most televised dance, including, for example, Twyla Tharp's Making Television Dance (1977) with all its special effects, does not literally count as screen dance.

Here I can imagine some complaints. On the one hand, some of you might say that even if the television screen is not equivalent to a film screen, it is like another sort of screen, namely the wire mesh on a screen door. Yet, if this is how you understand the notion of screen in "television screen," then you must admit that the category of screen dance is much more heterogeneous than it sounds, since the way in which one applies the concept to film dances versus TV dances is radically different, and, in some respects, contrary. The locution "screen dance" thus blurs important distinctions and muddies the waters, rarely an admirable tendency when trying to craft a concept. In addition, the analogy with the wire mesh on screen doors may not be a felicitous one to adopt here, since I assume that we would not want to call a live, three-dimensional dance, executed by live bodies, that is staged on the opposite side of a screen door an example of screen dance in the relevant sense.

Another complaint that some may have with my rough treatment of the idea of screen dance may be that when composing a film dance, a video dance, or a computer dance, one must be attentive to the dimensions of the picture plane on which one works. If it is a square or a rectangle, if it is in cinemascope or Todd-AO, the image composer must be aware of this - if only to make sure that viewers get to see what the composer intends them to see. And, more than that, if one hopes to make a genuinely effective dance image, one should study the shape of the visual expanse upon which one is working.

This is all true. And yet it is, I think, to be really talking about the frame, rather the screen, since it is the frame whose exact dimensions make certain compositions more efficacious than others. That is, for example, with film we are not actually talking about the surface onto which the image is projected, but the shape of that surface. Likewise, with regard to $\mathrm{TV}$, we are talking about image ratios and their relevance to placing figures saliently inside their borders. Though we may speak of sensitivity to the screen here, it is really just a shorthand way of referring to framing, whether what is framed appears in a phenomenologically deep space or a shallow one.

And finally, if you remain unmoved by any of the previous objections to the notion of screen dance, there is also the problem that the concept does not seem well prepared for the future. For we can readily imagine holographic dances and dances in virtual reality that we might wish to regard as part of our evolving tradition of moving-picture dance, but which will not require screens. And what of the developments that we cannot foresee? In the future there may be no screens, yet the practice of moving-picture dances may (and probably will) still be with us.

Given the problems with previous designations of the field, it seems useful to try a new tack. As already indicated, I propose to call the field moving-picture dance. This conceptualization has three components: "motion," "picture," and "dance." First, in order to belong to this category, an example must be a moving image. This requires that the work in question be made by a technology in which the possibility of movement is at least feasible. Most dances of this sort will either contain figures that are moving, or images that elicit the 
impression of movement by means of devices like fast editing or special effects. Though this covers a lot of ground, some of you may say it is not broad enough, since there are still dances, like Douglas Dunn's 101 (1974), and therefore that we shall want to count as part of the field images thereof. ${ }^{10}$ But if we make motion one of the criteria here, such efforts will be excluded.

This would be a problem if the requirement were that the image had to be moving; however, that is not how I've stated it. I've only required that it be made by means of a technology where movement is possible. So a film of a still dancer will nevertheless fall into the category, since movement is a possibility in film. It is not, on the other hand, a possibility with slide projections. So a slide of a still dance will not be counted in the category of motion-picture dance, though a comparable still film, even if it appears to be perceptually indiscernible from the slide, will so count.

Is this an arbitrary distinction? I don't think so. For in the film case, since movement is a possibility, the fact that the image has no movement is a pertinent stylistic choice. In order to plumb the significance of what the artist has done, we need to ask why she has chosen to make a still image. We need not ask that question about a slide, since movement is necessarily impossible in a slide. If the image could move, it wouldn't be a slide. Movement is not a possible choice with respect to a slide—all slides must be still—-so there is no point in asking why the slide is not moving. But if a film shows no movement, that is an unavoidable question, since in that case the artist eschews one of the fundamental possibilities of her technology.

Thus, because of its relevance to artistic choice, style, and significance, the choice of movement versus no movement is a defining feature of film, and other forms of moving images, whereas it is not a conceivable choice with respect to slides, or, for that matter, paintings and photographs of dance. That is why I state the motion condition so broadly in terms of the possibility of movement. Of course, most moving-picture dances move: either their figures move or devices like editing and special effects convey the impression of movement. This is what immediately differentiates them from other visual forms, such as paintings, sculptures, and photographs of dance.

The notion of moving-picture dance also requires that the moving images in question be pictures of dance. But this raises the question of what is meant by dance. Richard Lorber has attempted to define dance as "the sum of all non-functional movement behaviors" (8)." This does not seem quite right, however, since the mattress-moving in Yvonne Rainer's Room Service (1963) should count as dance movement, but it is functional. Indeed, the exploration of ordinary movement by the early postmodern dancers at Judson Church might appear to render the concept of dance utterly indefinable, since if ordinary movement is dance, then it would appear that any kind of movement could be dance. That is, dance cannot be defined in terms of its internal movement properties, like expressivity or rhythm.

That sounds persuasive, but it does not mean that we lack the wherewithal to differentiate dance from other sorts of behavior. Specifically, we may be able to identify something as a dance historically, even if we are unable to define it essentially. That is, dance, like the concept of a biological species, may be a historical concept-a concept whose members we determine, as we determine membership in a biological species, by telling narratives or genealogies of descent. So, something counts as a dance movement (or a dance stillness) if it is an example of a historically identifiable dance form or a recognizable descendent thereof. In 
order to establish that a candidate for membership in the category of dance is a recognizable descendant of a previous dance form or a combination of previous dance forms, we need to tell a plausible historical narrative of its evolution from bona fide origins, as we do when we explain how postmodern dance evolved dialectically from modern dance.

I will not deny that the notion of a historical concept deserves more attention than I have just given it. ${ }^{12}$ However, even the little that has been said should give you an inkling of how I propose to tackle the problem of whether or not we are dealing with a specimen of dance. Of course, if you have a better way of identifying dance, you are welcome to use that for the explication of the idea of moving-picture dance which, at this point, I am defining as an image array composed of movement from a recognizable dance vocabulary, where a dance vocabulary is identified either historically or by whatever means you have discovered.

But this is not yet the complete definition, since I have called the field "moving- picture dance" rather than "moving-image dance."What, if anything, hangs on talking about pictures rather than images? Pictures are things whose referents we recognize simply by looking. ${ }^{13}$ Pictures are of the kinds of things we find in the world - specific objects, events, persons, and actions. "Image" is a broader term of art, signifying any form that is visible. An image can be what is called nonfigurative, or nonobjective, or abstract. Jackson Pollock, Wassily Kandinsky, and Frank Stella are famous for their images, not for their pictures, since pictures are of recognizable things or, at least, recognizable kinds of things.

Thus, the term moving-picture dance narrows the field to visualizations of recognizable things, specifically to dances, which, it would seem, are necessarily composed literally of humans and human movement, or personifications thereof. So, at least according to me, when I claim that the concept of moving-picture dance describes our field of interest, I am saying that something belongs in our area if and only if it is a moving visual array of recognizably human movement or stillness (or a personification thereof) drawn from an identifiable existing dance vocabulary or a descendent therefrom. Or, more simply but less accurately: a moving-picture dance is a moving picture of dance movement.

Let me call this the central concept of moving-picture dance. As we shall see, it needs to be supplemented with another concept-what I will call the extended concept of moving-picture dance. But before we get there, allow me to say a few things about the central concept. I'm sure that some of you have already formulated objections to this characterization of what I allege to be the central concept of the field. These objections may take at least two forms: that the notion of moving-picture dance so defined is, in certain ways, too narrow and, in other ways, it is too broad. For some of you, it will be too narrow because it excludes too much, since it excludes what are called ballet mécaniques like Fernand Leger's and Oscar Fischinger's, on the one hand, and abstractions, such as Doris Chase's Circles I (1971), Rocker (1976), or Pelexi Radar (1981), on the other. I hope to deal with these shortcomings when I introduce the extended concept of moving-picture dance.

At the same time, the category, as I've sketched it, may seem too broad, since it includes things like film-dance documentations, sans editing, taken from a fixed-camera position. And many of you will argue that that is just not the kind of thing with which we are concerned. Even the notion of cine-dance gets closer than what I am calling the central concept of moving-picture dance.

This is a fair point, and it calls for immediate comment. From my perspective, the concept of moving-picture dance, as defined so far, only marks the genus of the things that 
concern us. Anything that centrally concerns us must fall into this genus as I've defined it. However, this genus includes several species, notably: moving-picture dance documentations, moving-picture dance reconstructions, and moving-picture dance constructions. As these labels perhaps already indicate, it is primarily moving-picture dance constructions that we generally gather to honor at festivals. So the preceding objection is an apt one to the definition of the genus of moving-picture dance, but the damage can be repaired when we categorize the subtending species in the genus and take note that one of themmoving-picture dance constructions - is the category that most interests us.

What exactly are these species? In order to get a handle on this, it pays to recall that moving-picture dance is a hybridization of two forms: motion pictures and dance. Thus, one way to differentiate these species is to examine the way in which each species relates these two constituents. One relation is that in which the dance is the predominant or lead element-where the motion picture subserves the dance element. That is moving-picture dance documentation. Another possibility is where the motion-picture component calls the tune. That is moving-picture dance construction. Between these two, there is the possibility where the motion-picture elements and the dance elements are co-equal determinants in the results; moving-picture dance reconstruction fills this category. ${ }^{14}$

In order to be a little less abstract, I will say something about each of these categories. Moving-picture dance documentations take advantage of technologies like cinema and video in order to imprint records of the past chemically, mechanically, and/or electronically in their medium. Documents of this sort are invaluable to dance historians and to choreographers involved in reconstituting the classics; they supply a temporal telescope into dance history. Traditionally, the preferred style of these documents is the frontal long-take single fixed-camera-position approach. Examples would include Virginia Brooks's 1983 video of the Dayton Contemporary Dance Company at the Riverside Dance Festival, Talley Beatty's 1948 bench piece from Jacob's Pillow, and the video documentation of the stage version of Li Chiao-Ping's Yellow River (1991).

Recently, moving-picture documentations have received a great deal of bad press, especially from dance notators. They argue that moving-picture documentations-or docudances - are not very good records, especially of historic choreography, because they restrict themselves to single performances, with a single cast of dancers replete with their personal mannerisms, taken from a single angle which may not always be the best one from which to notice, understand, and appreciate the relevant movement qualities. That is, docudance is a poor instrument for telling the dancer from the dance.

In this regard, notators have a point, though it may not be precisely the point they have in mind. For the complaints they voice really only pertain to a certain style of docudance, albeit a very pervasive style, but not to docudance as such. That is, the limitations they point to belong to one style of docudance and can be remedied easily by movingpicture dance documentators through countervailing stylistic strategies.

Undoubtedly, there are a great many examples of docudances that are too selective, that are restricted to a single performance, or that favor medium-long shots from a single camera position, and which, thereby, lose important details and dance qualities. But it is certainly within the resources of the moving-picture dance documentator to transcend these difficulties.

Despite appearances to the contrary, the notator has certain films and videos in mind when she chastises existing films and video records of dance. She has not really thought 
about the possibilities of docudance as such. For example, she has in mind the great many examples of films of a single performance where the camera holds back to a respectful long shot. But there are no grounds to think that a moving-picture dance documentation needs to be restricted to a single performance. A film can show many different ballerinas performing the character of Giselle, as one finds in the film A Portrait of Giselle (1982). Or, if one does not wish to interrupt a performance, one can provide alternative versions of the scenes in the sorts of appendices that are becoming more and more popular in laser discs, or one can nest the alternatives in the hypertext of a CD-ROM, or one can place them on the alternative tracks of a DVD. Indeed, in the 1980 docudance of Doris Humphrey's Two Ecstatic Themes (1931), two soloists, Carla Maxwell and Nina Watt, perform the dance in full_one after the other - thereby enabling the viewer to begin to discriminate the personal from the choreographic (the dancer from the dance).

The problem of the medium-long shot can be overcome by similar devices. If long shots obscure details, then take shots from many angles, including close shots, and locate them in appendices. This is not only a conceptual possibility. Sally Banes and Robert Alexander do just this in their document of Yvonne Rainer's Trio A (1978). And, of course, there is no reason why a moving-picture dance documentation cannot show a dance more than once from different angles, or at different camera speeds. Babette Mangolte's film of Trisha Brown's Water Motor (1978) presents the dance first at 24 frames per second and then in slow motion, affording what Vertov calls a microscope in time that enables one to attend to the dance in fine detail.

Once we realize that it is only a stylistic choice that limits moving-picture dance documentation to showing us a continuous stretch of choreography-once we realize that either parts or the entire performance can be taken from different vantage points for different reasons - then a solution to the problem of selectivity is within our reach. The notator presents the documentarian with a dilemma: either select variable camera positioning and editing, thereby doctoring the record, or go for the problematic medium-long shot, thereby occluding significant detail. But this is a false dilemma. For the documentarian can do both. She can shoot the dance from end to end from a medium shot, thereby rendering it in all its integrity, and then show us alternative views from more suitable angles of details of the dance, and even alternative views of parts of the dance as performed by different principal dancers. These alternative views can be presented either sequentiallythat is, in appendices following the dance proper-or as insets in medium-long shots via segmented or split screens, or, again, they can be nested in the hypertext of a CD-ROM. In short, the notator's argument against moving-picture dance documents rests upon exaggerating the limited imaginations and stylistic approaches of past documentarians. The notators, I believe, mistake such examples as inherent limitations of moving-picture dance documentation as such. But dance documentators, as we have seen, can surpass those limitations effortlessly, at least if they have enough money. This is not said in order to argue against the production of Labanotation scores of dance; in the best of all possible worlds, we should want such scores and moving-picture dance documentations.

If in the case of moving-picture dance documentations, the motion picture component is in the service of the dance, in the case of moving-picture dance reconstructions, the dance component and the motion picture component are more like co-contributors to the result..$^{15}$ The point of a dance reconstruction of this sort is to make the dance and its 
qualities accessible to the viewer. To this end, the reconstructor will deploy multiple camera positions, editing, close-ups, and the like in order to recreate the impression of the dance. Examples of what I have in mind include productions of the "Dance in America Series," such as the reconstruction of Western Symphony in the 1993 production Balanchine Celebration: Part II, directed by Matthew Diamond.

In these cases, I suggest that the moving-picture dance reconstruction is best understood as an interpretation of an already existing dance. Perhaps an analogy will be useful here. Just as the performers of a piece of music execute what we call an interpretation of an already existing work, so the moving-picture dance reconstructor, employing her complement of visual resources, makes an interpretation of a pre-existing dance or dance performance (which is itself already an interpretation).

The aim of musical performers is to make the musical work accessible to an audience; likewise, the moving-picture dance reconstructor aims at making a pre-existing theatrical performance of a dance accessible to an audience by, in effect, showing them how and where to look at a pre-existing dance, and how to organize the dance and its important patterns in their temporal experience. In effect, the moving-picture dance reconstruction is an interpretation of an interpretation, where the pre-existing performance is itself generally an interpretation of a pre-existing dance. Moreover, as there can be many acceptable performative interpretations of the same piece of music, so there can be many different, though acceptable, moving-picture dance reconstructions, each, in turn, making different aspects of the dance accessible to viewers.

In moving-picture dance reconstructions, the dance component and the motion picture component are co-equal in the sense that, though the reconstructor is constrained by the need for respecting the identity of the dance in question, the desired result is to render the dance accessible visually (and aurally) in a motion-picture format, thereby requiring that the dance be adjusted to the exigencies of the pertinent motion-picture mode of representation. This will often require interrupting and reorienting the movement of the dance in a battery of takes for maximal camera exposure. Moving-picture dance reconstruction requires a tender balance between the choreographer and the reconstructor, but it is not an impossible one to achieve.

Whereas the reconstructor is involved in remounting a past dance via motion pictures, the moving-picture dance constructor is aiming to produce a new work. To see what I'm getting at, it is useful to begin by recalling the modernist notion of cine-dance. There the idea was that a cine-dance is made for the screen, and that the way to test for success is to ask whether the dance could be realizable by theatrical means. Where it is not, that is taken as evidence that a new work has been created, one that relies essentially on the camera for its provenance. So a work like Hilary Harris's 9 Variations on a Dance Theme (1967) is a paradigmatic cine-dance in this tradition, since it is supposed that its penetrating geography of the body is not something obviously realizable on stage, dependent as it is on cinematic close-ups and framing.

Now, I have criticized the modernist bias of this conception, arguing that comparable theatrical realizability should not be the test of whether something counts as a moving-picture dance construction. Nevertheless, a piece of the notion of cine-dance may still be useful to us, namely that such a construction be a new work, one brought into being and shaped by the agency of the resources of the motion picture, such as editing, 
camera movement, camera placement, special effects, digital processing, motion capture, computer animation, and so on. This does not mean that the moving-picture dance constructor cannot use pre-existing dance material, as presumably Hilary Harris did, in the process of constructing something new by cinematic agencies; it only requires that the constructor be attempting to produce a new dance work in the process, rather than documenting or reconstructing one. Speaking of her work with Douglas Rosenberg entitled De L'Eau (1995), Li Chiao-Ping put this point nicely when she said that De L'Eau was not a translation of a work, but rather was the work. ${ }^{16}$

So the test of whether we have a moving-picture dance construction is whether the constructor intends to produce an autonomous work of art, using either pre-existing dance material or dance material expressly composed for interacting with whatever motion picture resources the constructor has at her disposal. On this construal, it makes no difference if a comparable dance work could be realized by other means, such as theatrical ones; what makes the difference is that new work in question was in fact produced through the agency of the motion picture, for example, by cinematic or videographic means. These means, moreover, need not be unique to the relevant medium. Thus, a long-take duo by Astaire and Rogers, composed for the camera, though perhaps in some sense realizable on a stage, still counts as a moving-picture dance construction, because it is a new work, a new dance, brought into existence by the agency of motion pictures. The issue is not whether the new work could have been produced in another art form, like theater, but whether it was brought into existence by the art form of motion pictures.

Earlier I said that with respect to moving-picture dance constructions, the motion picture component is dominant. The sense of "dominance" that I had in mind is that the choreographic ingredients involved, whether designed specifically for the occasion or derived from pre-existing material, are not transfigured into an integral, autonomous, original work of art until they are articulated in the idiom — whether essential or not — of motion pictures.

But then how are we to tell the difference between moving-picture dance reconstructions and moving-picture dance constructions, in cases where the dance construction is employing pre-existing dance material? Here we need to consider the artist's intention in producing the work: was she intending to create a new work or to re-interpret an already existing one? In the latter case, we have an instance of reconstruction, whereas in the former case, we are looking at a moving-picture dance construction.

Because of this reliance on authorial intention, it may be imaginable that we could have three perceptually indiscernible moving-picture dances: one a document, one a reconstruction, and one a construction comprised of pre-existing dance materials. How do we say which is which? It depends on whether the author intended to make a document or a reconstruction of an existing dance, or whether she intended to make something new, something with different qualities and different significations than any pre-existing dance. Is this a problem? I don't think so, since for art in general, it is the creator's intentions that fix the pertinent category of an artwork (Levinson 188); ${ }^{17}$ and, furthermore, where a constructor intends to create a new artwork but produces nothing more than what functions, upon reflection, as a document of a pre-existing dance, then, unless (like Warhol with his Brillo Boxes) she is making a reflexive comment, we will say that she has failed to realize her intention to construct a new artwork — which, all things being equal, is a reason to find her moving-picture dance construction unsuccessful. 
So far I have defined the genus of moving-picture dance and then further subdivided it into three species, of which the last, the moving-picture dance construction, is undoubtedly the one that we most care about, since it is the source of original artworks in this field. I claim that this is the central concept of motion dance, because most of the work that one will encounter at festivals devoted to this sort of work fall into this genus and, as well, one can expect to find examples of all three of its species on the program. Though, of course, one expects to find more moving-picture dance constructions than the other sorts, nevertheless, when some documentations and reconstructions appear, one is unlikely to hear too much grumbling, since, I submit, all three species coincide roughly with our intuitions about what fits naturally into our field of interest. That is, we all understand why documentations, reconstructions, and constructions have all found their way onto the program.

However, even if my formulations suit the least controversial examples of what concerns us, they do not cover everything. As indicated previously, by invoking the requirement that motion-picture dances be comprised of dance material-however straightforward that makes our scheme of categorization-it fails to accommodate the sorts of ballet mécaniques and nonfigurative movement abstractions that are also often regarded as part of the tradition of moving-picture dance. In order to deal with cases like this, I suggest that we introduce a second, extended (rather than central) concept of moving-picture dance, thereby hypothesizing that our field is really governed by two concepts rather than only one.

That is, the central concept of moving-picture dance needs to be supplemented by the extended concept of moving-picture dance. My suggestion for this second concept is that something is a moving-picture dance in the extended sense if the image component includes a significant amount of movement presented because it is interesting for its own sake. ${ }^{18}$ This movement may be of elements inside the frame or it may be an impression of movement generated by technical means, such as editing or special effects like pixilation (such as one finds in the work of Pooh Kaye). Where that movement is interesting in its own right, we have a case of moving-picture dance in the extended sense. For in these cases, we are apt to describe the movement as dance-like just because dance is the art form that specializes in the exhibition of movement for its own sake.

This is not all that dance does, of course, but when one is asked which of all the art forms specializes in the exhibition of movement for its own sake, dance seems the likeliest candidate. That is, dance is the pre-existing category under which we subsume movement presented because of its intrinsic interest as movement. Consequently, when we encounter a motion picture that exhibits a significant amount of movement in a way that is interesting for its own sake, we are naturally inclined to say that it is dance-like, or, in my terminology, an instance of moving-picture dance in the extended sense.

Here I must hasten to add that a set of movements may not only be interesting for its own sake, but interesting for other reasons as well. Thus, the aerial ballets in Bruce Lee's kung-fu films, what Douglas Rosenberg calls recoporealizations, are narratively interesting at the same time that they are interesting, indeed delightful and compelling, to watch for their own sake. My requirement is simply that the movement be at least interesting for its own sake, but it need not be exclusively so. Because, as well as being interesting for its narrative content, Bruce Lee's martial cine-choreography is also interesting for its own sake, we can call it a case of moving-picture dance in the extended sense. 
Moreover, if we accept the notion of motion picture dance in the extended sense, I think we can deal with the kinds of cases the central concept of motion picture dance leaves out. Ballet mécaniques present nonhuman movements as interesting for their own sake. Abstract movement pieces — such as Doris Chase's — can also be counted as movingpicture dance constructions in the extended sense, where they picture movement that is interesting for its own sake. Even constructions comprised of ordinary movement-such as Amy Greenfield's Tides (1982), Elaine Summers' lowa Blizzard (1973), Silvina Szperling's Bilingual Duetto (1994), and Ami Skanberg's warm-up Etude (1996) — may count as movingpicture dance movement in the extended sense, if the ordinary movement is exhibited in the context of a new artwork in a way that renders it interesting for its own sake. ${ }^{19}$

If we employ these two concepts of moving-picture dance-the central concept and the extended concept — I think that we can assimilate all the cases of dance-relevant motion pictures we want. Is there a problem with employing two concepts to define the field, rather than one? Perhaps some might worry that there is, because they fear that one concept, the central concept, is being implicitly privileged hierarchically over the other. But there is no reason to suppose that this must be the case. It is perfectly consistent with what I've proposed to agree that many moving-picture dances in the extended sense are superior to moving-picture dances more centrally in the category, including moving-picture dance constructions. Indeed, none of my categories are evaluative; they are all classificatory. A well-done moving-picture dance reconstruction can be aesthetically better than a lackluster or inept moving-picture dance construction.

In conclusion, I have developed a family of definitions designed to capture the range of things that I believe we feel intuitively drawn to include in the corpus of what I am now calling moving-picture dance, a label that I believe better encompasses the extension of things that concern us than do the more popular alternatives. Some readers, I know, have genuine reservations about definitional projects like mine because they fear that definitions, like Aristotle's definition of tragedy, have a tendency to turn into prescriptions - attempts by theorists to legislate what will count as art or art of a certain genre, like moving-picture dance. But I do not think that this definitional exercise has been legislative, because the framework I've offered is rather compendious: even if the central concept limits experiments to dance movement, the extended concept opens it to any kind of movement. This allows that anything can be grist for the artist's mill, so long as it has something to do with the possibility of movement. Can any conception be more liberal? Does anyone wish to include in the category something that has nothing whatsoever to do with movement? And, in any case, my definitions are not overly exclusive from the artistic point of view, since, of course, even if someone makes a work that somehow falls outside my framework, there is no implication in what I've proposed that it cannot be art or that it cannot be of great value.

So what's the problem?

\section{Notes}

1. For instance, to use a political example, certain definitions of what it is to be a human being have long been emancipatory instruments in struggles against racism and sexism.

2. Emshwiller, Ed. "Artist's Statement." Dance Perspectives 30 (Summer, 1967): 25. Print. 
3. This argument is developed in Noël Carroll, "Defining the Moving Image," in Theorizing the Moving Image. New York: Cambridge University Press, 1996. Print.

4. See Rosenberg, Douglas. "Recorporealizing the Body Via Screen Dance." Dance for the Camera Symposium. University of Wisconsin-Madison. 11 February 2000. Lecture.

5. Similar reasoning would pick out Cunningham's Blue Studio (1976) as a quintessential video dance, since in the chromakey segments, Cunningham, through the agency of video, is able to "dance across" an impossible series of landscapes.

6. For example, the creative geography that is so important in Shirley Clarke's A Dance in the Sun (1953) could be easily duplicated through video.

7. Copeland, Roger. "The Limitations of Cine-Dance." Filmdance: 1890's-1983. Ed. Amy Greenfield. New York: Filmdance Festival Catalogue, 1983. Print.

8. Andre Bazin was an influential French film theorist of the nineteen-forties and fifties who advocated the use of long-take, deep-focused shots - shots that allow the spectator's eye to rove across the image. Such shots approximate the conditions of seeing in real space and time, rather than breaking events apart by editing. Bazin defended this style in the name of realism. But clearly the kind of reliance on blocking in the single shot that he preferred could also be replicated in theater. See Andre Bazin's What Is Cinema? Vol. I. Berkeley: University of California Press, 1971. Print.

9. Jacques Tati was a French filmmaker who specialized in comedies_-such as Play Time (1967)_of everyday life, finding humor in its mundane events. One could say that he isolated comic moments in the stream of daily living, plucking laughs out of the quotidian. He also employed Bazinian techniques to this end, encouraging viewers to discover comic interactions in scenes, much as we find Waldo in the games of the same name. Woodberry's Invisible Dance (1981) shares a congruent sensibility, staging bursts of dance activity amidst the rush of Wall Street lunch breaks, and inviting us to find pre-staged dance moments in the seams and on the margins of the workaday hustle and bustle.

10. N.B. Amy Greenfield made a film of 101, though since I have unfortunately not seen it, I cannot say how still it actually is.

11. Lorber, Richard. "Experiments in Videodance." Dancescope 12.1 (Fall/Winter, 1977/78): 7-16. Print.

12. For further discussion of this historical approach (with respect to the issue of identifying art in general), see Chapter Five of Noël Carroll, Philosophy of Art: A Contemporary Introduction. London: Routledge, 1999. 249-264. Print. Also, see the suggested readings at the end of that chapter for more references.

13. For a defense of this view of pictures, see Noël Carroll, "The Power of Movies," in Theorizing the Moving Image (cited above), pp. 75-93.

14. Abstractly, there is a fourth possible permutation here: where the dance element and the motion picture element have nothing at all to do with each other. But if they have literally nothing to do with each other, then we are not dealing with a case of hybridization, but, rather, with two numerically independent works. Consequently, this possibility will never be realized literally in any moving-picture dance, where dance and image are physically imprinted in one object, and, therefore, should be of no concern to us.

15. In order to avoid terminological confusion here, let me emphasize that by "reconstruction"I am talking about reconstructions of existing dances by means of moving-picture technologies; I am not referring to things like Millicent Hodson's reconstruction of Le Sacre du printemps (1987) for the stage.

16. See Chiao-Ping, Li. "The Director/Choreographer Dialectic." Dance for the Camera Symposium. University of Wisconsin-Madison. 10 February 2000. Lecture.

17. Levinson, Jerrold. The Pleasures of Aesthetics. Ithaca: Cornell University Press, 1996. Print.

18. We will say that movement is interesting for its own sake, at least if the movement itself, apart from whatever other functions it performs, is delightful, arresting, fascinating, pleasurable, compelling, or riveting to look at (as movement), or because it is stimulating to think about (as movement), perhaps for theoretical reasons. Admittedly, this does not supply us with a definition of what it is for movement to be interesting for its own sake, but it should give the reader of an idea of the relevant ballpark.

19. Though the central concept of moving-picture dance is comprised of three species, I suspect that, when it comes to the extended concept, we are only dealing with the category of constructions. That is, I do not think that people are usually inclined to count documents of non-dance movements or even motion picture reconstructions thereof as moving-picture dance, even in the extended sense. The temptation only arises where the moving-picture dance work in question has some claim to being an autonomous, movement artwork. Some evidence for this is that one does not usually find such movement documents or reconstructions included in festivals for or catalogues of moving-picture dance works. 